\title{
PEMBUATAN KARTON SKALA INDUSTRI KECIL DARI CAMPURAN LIMBAH PEMBALAKAN DAN SLUDGE INDUSTRI KERTAS
}

\author{
(Manufacture of Paperboard in Small-Scale Industry from \\ the Mixture of Wood-Logging Wastes and Paper-Mill Sludge)
}

\author{
Oleh/By: \\ Han Roliadi $^{1)}$ \& Setyani Budi Lestari ${ }^{\text {1) }}$ \\ ${ }^{1)}$ Pusat Penelitian dan Pengembangan Hasil Hutan, Jln. Gunung Batu, Bogor \\ Tlp. (0251) 8633378; Fax (0251) 8633413
}

Diterima 2 Maret 2009, disetujui 22 April 2010

\begin{abstract}
A trial has been carried out on processing of wood-logging wastes into pulp and paperboard manufacture using the mixture of pulp from wood-logging wastes and paper-mill sludge at two various proportions, i.e. 50:50\% and $25: 75 \%$.

The processing of pulp from those wastes employed semi-chemical soda process in semi-pilot scale, using the conditions, i.e. alkali concentrations at $14 \%$ and $16 \%$, weight ratio of wastes to cooking liquor 1:5.5. Results revealed that the pulp from $14 \%$ alleali concentration suited better as the sludge mixture forpaperboard manufacture, based on pulp yield, alkeali consumption, and Kappa number.

The yield and physical as well as strength properties of paperboard from the mixture of pulp from wood-logging wastes (50\%) and paper-mill sludge (50\%) together with additives were higher than those from the mixture with $25: 75 \%$ proportion (with additives). Further, the physical/strength properties of paperboard from the mixture with 50:50\% proportion were higher than consecutively those produced from small-scale paperboard factory using the mixture of waste paper (50\%) and sludge (50\%) without additives; and those from the mixture of plantation forest's wood-logging wasate pulp and paper-mill sludge (with additives and at 50:50\% proportion). This suggests the prospective use of pulp from natural production forest's wood-logging wastes as a substitute material mixed with sludge, in place of waste paper currently used by small-scale paperboard industries.
\end{abstract}

Keywords: Logging wastes, natural production-forest, paperboard, paper-mill sludge, pulp

\section{ABSTRAK}

Percobaan pembuatanpulp dan karton skala industri kecil dilakukan menggunakan campuran pulp limbah pembalakan kayu hutan alam produksi (KHAP) dan sludge industri kertas pada 2 proporsi yaitu 50:50\% dan $25: 75 \%$.

Pengolahan limbah pembalakan KHAP menjadi pulp dilakukan dengan proses semi kimia soda panas pada skala semi pilot dengan kondisi konsentrasi alkali $14 \%$ dan $16 \%$, dan perbandingan berat limbah dengan larutan pemasakan 1:5,5. Hasil penelitian menunjukkan bahwa pulp pada konsentrasi alkali $14 \%$ lebih sesuai sebagai bahan pencampur sludge untuk pembuatan karton, ditinjau dari rendemen pulp, konsumsi alkali, dan bilangan kappa. 
Rendemen dan sifat fisik dan kekuatan karton dari campuran pulp limbah pembalakan KHAP $(50 \%)$ dan sludge (50\%) berikut bahan aditif, lebih tinggi dibandingkan dengan dari campuran pada proporsi $25: 75 \%$ (juga dengan aditif). Selanjutnya, sifat fisik/kekuatan karton dari proporsi campuran 50:50\% tersebut lebih tinggi dari pada sifat karton produksi industri rakyat dari campuran kertas bekas $(50 \%)$ dan sludge ( $50 \%)$ tanpa aditif, dan banyak memenuhi persyaratan karton komersial; dan juga lebih tinggi dari pada sifat karton dari campuran pulp limbah pembalakan kayu hutan tanaman dan sludge (pada proporsi $50: 50 \%$, dan dengan aditif pula). Penelitian ini bertujuan membuat karton dari campuran limbah, pembalakan kayu hutan alam produksi (KHAP) dan sludge industri kertas (SIK). Dengan demikian pulp limbah pembalakan kayu hutan alam berprospek cerah sebagai bahan substitusi campuran sludge pada industri karton rakyat yang menggunakan kertas bekas.

Kata kunci: Limbah pembalakan, hutan alam produksi, kertas bekas, sludge industri kertas, pulp, karton

\section{PENDAHULUAN}

Limbah pembalakan kayu hutan alam yang terbentuk selama ini hanya dibiarkan di tempat penebangan hingga membusuk. Di samping itu, limbah tersebut sekiranya diterpa oleh sinar matahari akan mengering sehingga mudah terbakar baik disengaja atau tidak. Selanjutnya terbakarnya limbah tersebut dapat menyebabkan kebakaran hutan, sekaligus mengakibatkan pemanasan global (emisi karbon ke atmosfir). Di sisi lain, industri karton skala kecil yang ada saat ini mengalami kesulitan mendapatkan bahan baku serat berupa pulp dan kertas bekas dalam jumlah cukup dan harga dapat diterima oleh industri tersebut (Anonim, 2007 dan 2009). Salah satu usaha yang dilakukan industri karton skala kecil untuk mengatasi masalah tersebut adalah dengan cara memproduksi karton menggunakan sludge dari limbah industri kertas yang potensinya cukup berlimpah sebagai bahan baku serat utamanya dan kertas bekas sebagai pencampur saja karena harganya cukup mahal (Rina, et al., 2002; Komarayati et al., 2005). Akibatnya, produksi karton ini tidak dapat memenuhi permintaan kualitas karton dari beberapa produsen produk jadi skala kecil, seperti buku-buku pelajaran, sepatu, tas, dan pakaian jadi. Ini disebabkan sifat sludge yang higroskopis, berserat pendek, dan mengandung bahan bukan serat (Maybee, 1999).

Terkait dengan segala uraian di atas, guna mengatasi limbah pembalakan hutan alam produksi dan membantu kesulitan industri karton rakyat mendapatkan bahan baku pulp dan kertas bekas, Pusat Litbang Hasil Hutan (P3HH), Bogor telah melakukan percobaan pembuatan arton pada skala industri kecil dari campuran pulp limbah pembalakan kayu hutan alam produksi dan sludge industri kertas dengan penggunaan aditif (bahan pengisi kaolin, bahan retensi tawas/alum sulfat, perekat tapioka, dan darih rosin (rosin soap).

\section{BAHAN DAN METODE}

\section{A. Bahan dan Alat}

Bahan baku utama yang digunakan adalah limbah pembalakan kayu hutan alam produksi (KHAP), yang memiliki berat jenis 0,28-0,49 di mana diambil dari Kabupaten Toba Samosir, Sumatera Utara. Sedangkan, sludge diambil dari pabrik kertas berlokasi di Cibitung (Bekasi). 
Bahan kimia yang digunakan mencakup soda api $(\mathrm{NaOH})$, barium khlorida $\left(\mathrm{BaCl}_{2}\right)$, asam khlorida $(\mathrm{HCl}) 0,1 \mathrm{~N}$, indikator fenolthalein, kalium permanganat $\left(\mathrm{KMnO}_{4}\right) 0,1 \mathrm{~N}$, air suling, asam sulfat $\left(\mathrm{H}_{2} \mathrm{SO}_{4}\right)$, kalium iodida $(\mathrm{KI})$, natrium tiosulfat $\left(\mathrm{Na}_{2} \mathrm{~S}_{2} \mathrm{O}_{3}\right)$, indikator kanji, dan aditif (bahan pengisi kaolin, bahan retensi tawas/alum sulfat), bahan perekat tapioka, bahan sizing rosin soap).

Peralatan yang digunakan untuk produksi pulp adalah ketel pemasak skala semi pilot hasil rekayasa $\mathrm{P} 3 \mathrm{HH}$ (Bogor), bak pencuci serpih hasil pemasakan, Hollander beater, dan stone refiner untuk penyempurnaan pemisahan serat. Sedangkan peralatan yang digunakan untuk pembentukan lembaran karton terdapat di industri karton skala kecil di Desa Adikarso, Kabupaten Kebumen (Provinsi Jawa Tengah), mencakup Hollander beater, stock chest, mesin kertas Fourdrinier, pengering lembaran karton menggunakan sinar matahari, calendering untuk pengepresan lembaran karton, dan alat pemotong dan pengepakan lembaran karton. Peralatan yang digunakan untuk pengujian sifat fisik lembaran karton adalah tearing tester untuk menetapkan indeks retak (burst index), tensile tester untuk indeks tarik, dan ring crush tester untuk ketahanan lingkar.

\section{B. Metode}

\section{Pembuatan pulp dari limbah pembalakan kayu}

a. Penyiapan serpih kayu

Limbah pembalakan KHAP dijadikan serpih kayu berukuran panjang 2-3 cm, lebar 2$2,5 \mathrm{~cm}$ dan tebal 0,2-0,3 cm dengan menggunakan mesin penyerpih kayu (wood chipper) dan dikeringkan di tempat terbuka hingga mencapai kadar air kering udara sekitar $12-15 \%$.

b. Pemasakan serpih limbah pembalakan KHAP menjadi pulp.

Serpih limbah pembalakan kayu tersebut di masak pada ketel pemasak skala semi pilot bertekanan udara tertutup hingga mencapai 1,5 atmosfir, berkapasitas $50 \mathrm{~kg}$ serpih kayu kering oven atau $125 \mathrm{~kg}$ menggunakan proses semikimia soda panas tertutup. Kondisi pemasakan yang digunakan adalah konsentrasi alkali 14\% dan 16\% selama 3 jam nulai suhu kamar hingga mencapai suhu maksimum sekitar $120^{\circ} \mathrm{C}$, perbandingan serpih dengan larutan pemasak sebesar 1:5,5, dan tekanan ketel pemasak sekitar 1-1,5 atmosfir.

Selesai pemasakan, serpih lunak dipisahkan dari larutan pemasak, selanjutnya serpih dicuci sampai bebas dari sisa larutan pemasak atau air pencuci mencapai kondisi jernih. Serpih lunak hasil pencucian diberi perlakuan mekanis dengan cara menguraikan seratnya dengan menggunakan Hollander beater dan stone refiner pada konsistensi 3-4\% hingga mencapai derajat kehalusan pulp untuk karton sekitar $400 \mathrm{ml}$ CSF (Canadian Standard Freeness). Pulp yang diperoleh dikurangi airnya pada alat sentrifus serta ditetapkan rendemennya.

\section{Pembuatan lembaran karton}

Pembuatan karton skala kecil dilakukan di industri karton rakyat, dengan mengacu pada prosedur SNI 14-0489-2005 (Anonim, 2005). Campuran bahan serat berupa pulp limbah KHAP dan sludge bervariasi pada dua proporsi yaitu 50:50\% dan 25:75\%. Bahan aditif yang ditambahkan pada campuran tersebut adalah pengisi (kaolin) sebanyak $5 \%$, tawas $2 \%$, bahan perekat tapioka $4 \%$, dan rosin soap $2 \%$ masing-masing dari berat bahan serat kering oven. Campuran tersebut dimasukkan dalam Hollander beater, lalu ditambahkan air hingga tercapai konsistensi 4\% dan difibrilisasi sampai mencapai derajat kehalusan 300-350 ml CSF. 
Sesudahnya, campuran tersebut dibentuk menjadi lembaran karton pada mesin kertas tipe Fourdrinier, dengan target gramatur $300-350 \mathrm{~g} / \mathrm{m}^{2}$. Lembaran karton basah yang terbentuk dikempa dingin dengan mesin calendering, dikeringkan lalu dipotong pada mesin pemotong menjadi berukuran $90 \mathrm{~cm}$ (panjang) dan $80 \mathrm{~cm}$ (lebar), dan selanjutnya ditimbang untuk menetapkan rendemen karton yang diproduksi, dan diambil contoh untuk penetapan sifat fisik dan kekuatan lembaran karton tersebut.

\section{Pengujian sifat pulp dan karton}

Sifat pulp hasil pengolahan KHAP yang diamati adalah rendemen pulp, bilangan kappa, dan konsumsi alkali. Rendemen ditetapkan menurut standar TAPPI T214SU-71 (Anonim, 1972 dan 1993), bilangan kappa menurut standar SNI 14-0409-2008 (Anonim, 2008), dan konsumsi alkali menurut standar TAPPI T525HM-85 (Anonim, 1993). Selanjutnya, sifat fisik dan kekuatan lembaran karton yang diamati meliputi gramatur, indeks sobek, indeks retak, indeks tarik, dan ketahanan lingkar (ring crush), berturut-turut menurut standar SNI 14-0440-2006 (Anonim, 2006), SNI 14-0439-1989, SNI 14-0436-1989, SNI 14-0437-1989, dan SNI 14-0583-1989 (Anonim, 1989). Cara pengambilan contoh uji pada lembaran karton untuk keperluan uji sifat fisik dan kekuatan tersebut dilakukan menurut SNI 14-0489-1989 (Ánonim, 1989).

\section{Analisis Data}

\section{Data sifat pengolahan pulp}

Data sifat pengolahan pulp dari limbah pembalakan KHAP (rendemen pulp, konsumsi alkali, dan bilangan kappa) ditelaah menggunakan rancangan acak lengkap dengan faktor perlakuan konsentrasi alkali $(\mathrm{NaOH})$ dalam dua taraf $(14 \%$ dan 16\%), masing-masing dengan ulangan sebanyak $3 \mathrm{kali}$. Data respons yang diamati adalah rendemen pulp, konsumsi alkali, dan bilangan kappa

\section{Data sifat fisik dan kekuatan lembaran karton}

Penelaahan sifat fisik dan kekuatan lembran karton menggunakan rancangan acak lengkap. Sebagai perlakuan adalah campuran pulp limbah pembalakan KHAP dan sludge industri kertas pada dua proporsi (50:50\%) dan (25:75\%), masing-masing dengan bahan aditif dan diberi notasi berturut-turut T1 dan T2; dan kertas karton produksi industri rakyat (sebagai pembanding) dari campuran campuran kertas bekas dan sludge industri ketas pada proporsi $50: 50 \%$, tanpa aditif dan diberi notasi $\mathrm{K}$. Ulangan dari masing-masing taraf perlakuan tersebut dilakukan sebanyak 5 kali. Selanjutnya, data sifat karton yang ditelaah mencakup rendemen karton, gramatur, indeks retak, indeks sobek, indeks tarik, dan ketahanan lingkar.

\section{HASIL DAN PEMBAHASAN}

\section{A. Sifat Pengolahan Pulp dari Limbah Pembalakan Kayu}

Analisis keragaman menunjukkan bahwa pengaruh konsentrasi alkali nyata terhadap rendemen dan sifat pengolahan pulp lainnya yaitu konsumsi alkali dan bilangan kappa (Tabel 1). Penelaahan lebih lanjut dengan analisa tersebut mengindikasikan bahwa pada konsentrasi alkali 14\% ternyata rendemen pulp dan bilangan kappa lebih tinggi, sedangkan konsumsi 
alkali lebih rendah dibandingkan dengan pada konsentrasi 16\% (Tabel 2). Lebih rendahnya rendemen pulp pada konsentrasi alkali 16\% diduga terjadi lebih banyak pelarutan lignin dan degradasi karbohidrat dibandingkan pada konsentrasi 14\%. Kedua rendemen pada dua konsentrasi alkali tersebut $(82,92 \%$ dan $81,59 \%)$ masih terletak pada selang rendemen pengolahan pulp semi kimia (70-85\%) (Smook and Kocurek, 1992). Selanjutnya bilangan kappa yang tinggi pada konsentrasi alkali 14\% karena pulp lebih kaku untuk karton. Sedangkan konsumsi alkali yang lebih rendah pada konsentrasi tersebut lebih menghemat pemakaian bahan kimia. Atas dasar nilai skor yang tertinggi dan merupakan manipulasi uji beda jarak Tukey atau beda nyata jujur (BNJ), maka pulp limbah pembalakan hutan alam produksi pada konsentrasi alkali $14 \%$ lebih sesuai sebagai campuran dengan sludge industri kertas untuk dibuat lembaran karton (Tabel 2).

\section{B. Pembentukan Lembaran Karton}

Rendemen karton dari campuran pulp limbah pembalakan KHAP dan sludge industri kertas pada proporsi 50:50\% lebih besar dibandingkan dengan pada proporsi (25:75\%) yaitu berturut-turut 79,11\% dan 76,33\% (sebelum pemotongan karton), dan $72,82 \%$ dan $68,29 \%$ (sesudah pemotongan menghasilkan karton dengan ukuran tertentu), seperti disajikan pada Tabel 3. Ini mengindikasikan bahwa pada sludge banyak terdapat serat pendek dan bahan bukan serat khususnya aditif (Maybee, 1999). Kedua rendemen tersebut masih dalam selang rendemen karton yang umum diperoleh pada industri karton rakyat atau skala kecil yaitu $75-85 \%$ (sebelum pemotongan) dan 68-78\% (sesudah pemotongan) (Roliadi dan Pasaribu, 2005).

Tabel 3. Rendemen lembaran karton dari campuran pulp limbah pembalakan hutan alam produksi (KHAP) dan sludge industri kertas (SIK)

Table 3. Yield of paperboard from the mixture of natural production forest woodlogging waste's (NPFWLS) pulp and paper-mill sludge(PMS)

\begin{tabular}{|c|c|c|c|}
\hline \multirow{2}{*}{ No } & \multirow{2}{*}{$\begin{array}{l}\text { Macam bahan serat } \\
\text { ( Kinds of fiber stocks) }\end{array}$} & \multicolumn{2}{|c|}{ Rendemen (Yield), \% } \\
\hline & & I & II \\
\hline A & Hasil percobaan (Experiment results) & & \\
\hline 1 & $\begin{array}{l}50 \% \text { pulp limbah KHAP (NPFWL } S \text { pulp })+ \\
50 \% \text { SIK (PMS) }\end{array}$ & $79,11 ? 5,11$ & $72,82 ? 4,78$ \\
\hline 2 & $\begin{array}{l}25 \% \text { pulp limbah KHAP (NPFWLS pulp) }+ \\
75 \% \text { SIK (PMS) }\end{array}$ & $76,35 ? 6,12$ & $68,29 ? 3,56$ \\
\hline $\begin{array}{ll}\mathrm{B} \\
& 1\end{array}$ & $\begin{array}{l}\text { Pembanding (Comparison) } \\
50 \% \text { kertas bekas (waste paper) }+50 \% \text { SIK } \\
(P M S)\end{array}$ & $75-85$ & $68-78$ \\
\hline
\end{tabular}

Keterangan (Remarks): I = setelah pengeringan, dan sebelum pemotongan (after the drying, and before cutting); $I I=$ Setelah pemotongan (after cutting)

Analisis keragaman menunjukkan bahwa pengaruh perlakukan (karton dari campuran pulp limbah pembalakan KHAP dan sludge pada dua proporsi yaitu 50:50\% dan 25:75\%, dan karton produksi industri rakyat) berpengaruh nyata terhadap sifat fisik dan kekuatan karton (Tabel 4). Penelaahan lebih lanjut dengan uji BNJ mengindikasikan bahwa gramatur 
karton dari campuran pulp limbah pembalakan dan sludge pada proporsi 50:50\% lebih tinggi dibandingkan pada proporsi $25: 75 \%$ (Tabel 5). Hal ini memperkuat dugaan lagi bahwa pada sludge terdapat serat terfragmentasi, fines, dan bahan bukan serat sehingga mudah lolos pada saat pembentukan lembaran karton pada mesin kertas Fourdrinier. Akibatnya, semakin tinggi proporsi campuran sludge, maka gramatur karton menurun. Selanjutnya, gramatur karton pada ke dua proporsi tersebut memenuhi target gramatur (300-350 gram $\left./ \mathrm{m}^{2}\right)$ dan masih di bawah gramatur produksi industri rakyat (Roliadi dan Pasaribu, 2005).

Ditinjau dari sifat kekuatan (indeks sobek, indeks retak, indeks tarik, dan ketahanan lingkar) ternyata sifat karton dari campuran pulp limbah pembalakan KHAP dan sludge pada proporsi 50:50\% jauh lebih tinggi dari pada sifat karton tersebut pada proporsi $25: 75 \%$, di mana ke dua proporsi tersebut menggunakan aditif (Tabel 5), dan juga lebih tinggi dari pada sifat karton produksi industri rakyat yang menggunakan campuran kertas bekas $(50 \%)$ dan sludge $(50 \%)$ tanpa bahan aditif. Pernyataan ini diperkuat dari evaluasi total skor yang merupakan hasil manipulasi uji BNJ (Tabel 5). Untuk kasus campuran limbah pembalakan KHAP dan sludge pada dua variasi proporsi tersebut, ini memperkuat indikasi lagi bahwa pada sludge terdapat serat terfragmentasi, fines, dan bahan bukan serat sehingga sifat kekuatan karton pada proporsi campuran sludge $75 \%$ lebih rendah dibandingkan pada proporsi $50 \%$. Selanjutnya, ketahanan lingkar karton yang cenderung menurun dengan makin besarnya proporsi sludge hingga $75 \%$ tersebut memperkuat dugaan bahwa sludge mengurangi kekakuan karton sehingga perlu dicampur dengan pulp kayu atau bahan berserat-lignoselulosa lain hingga proporsi tertentu.

Tabel 6. Sifat fisik dan kekuatan karton hasil percobaan dari campuran pulp limbah KHAP dan SIK, dibandingkan sifat karton dari campuran pulp limbah pembalakan kayu hutan tanaman (KHT) dan SIK

Table 6.Physical and strength properties of paperboard from the mixture of NPFWLS pulp and PMS (1), compared with those of paperboard from the mixture of plantation forest's wood-logging waste(PFWLS) pulp and PMS (2)

\begin{tabular}{|c|l|c|c|}
\hline \multirow{2}{*}{ No. } & \multicolumn{1}{|c|}{$\begin{array}{c}\text { Sifat } \\
\text { (Properties) }\end{array}$} & \multicolumn{2}{|c|}{ Macam bahan serat(Kinds of fiber suffs) } \\
\cline { 3 - 4 } & \multicolumn{1}{|c|}{$\begin{array}{c}\text { Pulp KHAP + SIK } \\
\text { (NPFWLS pulp + PMS) }\end{array}$} & $\begin{array}{c}\text { Pulp KHT + SIK *) } \\
(\text { PFWLS pulp + PMS) *) }\end{array}$ \\
\hline 1 & $\begin{array}{l}\text { Bobot dasar (Basis weight) } \\
\mathrm{g} / \mathrm{m}^{2}\end{array}$ & $318,23 ? 26,42$ & $322,58 ? 19,58$ \\
\hline 2 & $\begin{array}{l}\text { Indeks retak/pecah (Burst } \\
\text { index), } \mathrm{kN} / \mathrm{g}\end{array}$ & $0,60 ? 0,24$ & $0,61 ? 0,23$ \\
\hline 3 & $\begin{array}{l}\text { Indeks sobek (Tear index), } \\
\text { mNm } / \mathrm{g}\end{array}$ & $4,24 ? 0,02$ & $4,11 ? 0,03$ \\
\hline 4 & $\begin{array}{l}\text { Indeks tarik (Tensile index), } \\
\text { Nm/g }\end{array}$ & $19,69 ? 0,33$ & $16,57 ? 0,28$ \\
\hline 5 & $\begin{array}{l}\text { Ketahanan lingkar (Ring } \\
\text { crush), kgf }\end{array}$ & $20.87 ? 2,08$ & $19,27 ? 1,94$ \\
\hline
\end{tabular}

Sumber (Source): Roliadi dan Pasaribu (2006) 
Lebih tingginya sifat kekuatan karton dari campuran 50\% pulp limbah pembalakan KHAP dan $50 \%$ sludge industri kertas (dengan menggunakan aditif) dari pada sifat karton produksi industri rakyat yang menggunakan campuran 50\% kertas bekas dan 50\% sludge (tanpa aditif) memperkuat indikasi bahwa bahan aditif (kaolin sebagai bahan pengisi, tawas/alum sulfat sebagai retensi, dan tapioka dan rosin soap sebagai perekat) ikut berperan memperbaiki kekuatan dan kekakuan karton. Lebih lanjut, sifat fisik dan kekuatan karton dari campuran pulp limbah pembalakan KHAP dan sludge (pada proporsi 50:50\%) banyak memenuhi persyaratan karton komersial dan standar chipboard (Tabel 5), kecuali indeks sobek dan indeks retak. Diharapkan hal tersebut dapat diperbaiki dengan penggunaan lebih banyak bahan perekat tapioka dan rosin soap.

Selanjutnya dibandingkan dengan sifat fisik dan kekuatan karton dari campuran pulp limbah pembalakan kayu hutan tanaman dan sludge industri kertas (juga pada proporsi 50:50\%), ternyata sifat karton dari campuran pulp limbah pembalakan KHAP dan sludge industri kertas tersebut masih lebih tinggi (Tabel 6). Diduga ini ada kaitannya dengan porsi kayu muda (juvenile wood) yang tinggi pada kayu hutan tanaman.

\section{KESIMPULAN DAN SARAN}

1. Ditinjau dari rendemen pulp, konsumsi alkali, bilangan kappa, maka pembuatan pulp dari limbah pembalakan kayu hutan alam produksi (KHAP) dengan proses semikimia soda panas pada ketel pemasak bertekanan dan konsentrasi alkali 14\% berindikasi layak secara teknis sebagai bahan pencampur dengan sludge industri kertas untuk pembuatan karton.

2. Rendemen karton dari campuran pulp limbah pembalakan KHAP dan sludge industri kertas pada proporsi $50: 50 \%$ dan $25: 75 \%$ terletak dalam selang rendemen industri karton rakyat/skala kecil yaitu $75-85 \%$ (sebelum pemotongan) dan $68-78 \%$ (sesudah pemotongan). Semakin tinggi proporsi sludge, rendemen tersebut cenderung menurun.

3. Sifat fisik dan kekuatan karton dari campuran pulp limbah pembalakan KHAP dan sludge pada proporsi $50: 50 \%$ berikut bahan aditif masih lebih baik dibandingkan dengan sifat karton berturut-turut dari campuran 25\% pulp limbah pembalakan KHAP dan $75 \%$ sludge (juga dengan bahan aditif yang sama), dari campuran pulp limbah pembalakan kayu hutan tanaman dan sludge pada proporsi $50: 50 \%$ berikut aditif, dan juga lebih baik dari pada sifat karton produksi industri rakyat (dari campuran 50\% kertas bekas dan 50\% sludge, tetapi tanpa aditif).

4. Sifat fisik/kekuatan karton dari campuran pulp limbah pembalakan KHAP (50\%) dan sludge $(50 \%)$ tersebut banyak memenuhi persyaratan karton komersial dan standar chipboard, sehingga berindikasi layak secara teknis sebagai bahan baku industri karton rakyat skala kecil yang menggunakan bahan baku campuran kertas bekas dan sludge di mana industri tersebut dewasa ini mengalami kesulitan pasokan kertas bekas. 


\section{DAFTAR PUSTAKA}

Anonim. 1972. TAPPI (Technical Association of the Pulp and Paper Industry)'s testing Procedures. Numerical index of TAPPI standard and suggested method. Atlanta, Georgia.

1989. Cara uji ketahanan sobek (SNI 14-0439-1989), ketahanan retak (SNI 14 0436-1989), dan ketahanan tarik (SNI 14-0583-1989) kertas dan karton. Badan Standardisasi Nasional. Jakarta.

1993. TAPPI's test method. TAPPI Press. Atlanta, Georgia.

2005. Cara penyediaan lembaran pulp untuk uji sifat fisik (SNI 14-0489-2005). Badan Standardisasi Nasional. Jakarta.

2006. Cara uji gramatur (SNI 14-0440-2006) kertas karton. Badan Standardisasi Nasional. Jakarta.

2007. Indonesian Pulp and Paper Industries. Directory 2007. Indonesian Pulp and Paper Association. Jakarta.

2008. Cara uji bilangan kappa pulp (SNI 14-0409-2008). Badan Standardisasi Nasional. Jakarta.

. 2008a. Standar chipboard di Pabrik Kertas Bekasi Teguh. Bekasi,Jawa Barat.

. 2009. Hentikan konversi hutan. Harian Kompas, tanggal 20 Mei 2009, Hlm. 44. Jakarta.

Komarayati, S., E. Santoso, dan Gusmailina. 2005. Kajian teknis dan ekonomis produksi dan pemanfaatan pupuk organik mikorhiza (POM) dari sludge industri pulp untuk tanaman HTI. Laporan Hasil Penelitian. Pusat Penelitian dan Pengembangan Hasil Hutan. Bogor.

Maybee, W. 1999. Comparative study on the chemical composition of paper-mill sludge. Ph.D. candidate. Website: www.chem-eng.utoronto.ca/-pphone/Research/ Othermabee.html. Diakses 5 Maret 2002.

Pasaribu, R.A. dan H. Roliadi. 2005. Teknologi produksi karton skala kecil dari limbah pembalakan hutan alam produksi dan hutan tanaman. Laporan Hasil Penelitian. Pusat Penelitian dan Pengembangan Hasil Hutan. Bogor.

Prakosa, M. 2002. Kebijakan rehabilitasi dan konservasi sumber daya hutan. Policy Paper. Departemen Kehutanan. Jakarta.

Rina, S.S., S. Purwanti, H. Hardiani, dan S. Surachman. 2004. Pengaruh kompos dan limbah lumpur IPAL industri kertas terhadap tanaman dan tanah. Prosiding Seminar Teknologi Selulosa, tanggal 12 Desember 2004. Balai Besar Penelitian dan Pengembangan Industri Selulosa. Bandung. 
Roliadi, H. dan R.A. Pasdaribu. 2005. Teknologi produksi karton skala kecil dari limbah pembalakan kayu hutan alam produksi dan hutan tanaman. Laporan Hasil Penelitian. Pusat Litbang Hasil Hutan. Bogor.

. 2006. Analisa finansial teknologi tepat guna produksi karton skala industri kecil dari campuran limbah pembalakan kayu HTI dan sludge industri kertas. Laporan Hasil Penelitian. Pusat Litbang Hasil Hutan. Bogor.

Smook, G.A. dan M.J. Kocurek. 1992. Handbook for Pulp and Paper Technologists. TAPPI. Atlanta, GA.

\section{UCAPAN TERIMA KASIH}

Dengan tersusunnya tulisan, penulis mengucapkan terima kasih menyampaikan rasa penghargaan yang tinggi pada Bapak Ir. Ridwan A. Pasaribu, MS., Peneliti Utama pada Pusat Litbang Hasil Hutan (Bogor) yang telah banyak menyumbangkan tenaga dan pikirannya dalam kegiatan penelitian terkait dengan tulisan ini. 